\title{
"I have learned - It is about something that happened in the past!" - Time, space and human interaction in different perceptions of learning at work
}

\section{Elina Maslo}

This article is based on the empirical material collected when piloting new methodology in the study on working places as learning spaces. The article deals with different perceptions of learning and illustrates how different understandings of learning are constructed by two employees working at the same workplace. Using categories of spatial analysis the article show a hybrid space - a space when work and life meet each other and create new dynamics and inspirations for learning.

Keywords: working place, learning space, different perceptions, learning as multidimensional process

\section{Introduction}

Preparing for a new comparative study in the research network on workplace learning, researchers tested different ways of asking people about their learning at work. In one of the pilot projects, a very interesting conversation about learning took place right after asking the question about learning at work. It seemed that all participants in this conversation had different perceptions of what learning is. In this article, I will analyse this conversation in order to understand how different understandings of learning have been constructed by two persons from the respective workplace.

Learning is an extremely complex multidimensional process that happens differently to everyone. We are dealing with an extremely complex system of interactions between and within the individuals, between the individuals and their environment, and a host of subjective parameters, such as perceptions, emotions, 
attitudes and values. Learning, aside from being a cognitive process, is also an emotional and social process.

These highly subjective processes are difficult to study. Therefore, in this study, a participatory photo interview (Kolb, 2008) is used in order to come as close as possible to persons' lived experiences and personal reflections about their own learning (van Manen, 1991). By capturing learning moments in everyday activities at work in a way a person perceives these as learning moments, and telling about these moments to the researchers, the persons allow us to get an insight into their unique, practical, emotional and symbolic life in the concrete historical context (Kramsch, 2009).

There are many reasons why we need more knowledge about human learning in general and human learning at work. One of them is the increasing complexity and changeability of working and learning spaces, demanding new forms of knowledge, new forms of work and new forms of learning. Learning spaces become more multiple and diverse, more fluent, and the borders between working space and living space are constantly changing, and so is the development of the technology. These complexities are the focus of interest to spatial theories, which aim to acquire an interdisciplinary relational understanding of how these spaces are constructed, and how they acquire meaning through human actions: "The spaces in which education and learning take place are undergoing almost continual transformation" (Brooks, Fuller, Waters, 2012, 1). This paper will perhaps take us one step further in the development of the understanding of learning as a multidimensional process in transformative learning spaces.

For this paper, I have chosen one conversation, which I analyse in order to understand, how learning spaces at work are constructed differently by the participants in the study. After presenting the pilot project, the article gives the state of the art of the discussion on working places as learning spaces. Then, I describe the approach to the study, its context, and finally - the analysis of the conversation and the two different visions of learning at work.

\section{Pilot project - workplace learning at "The B\&B-House"}

This article is based on the empirical material collected while piloting methodology for the study "Working Places as Learning Spaces: Contextualising lifelong learning in Asia and Europe" conducted by the research network on workplace learning of ASEM Lifelong Learning Hub in 2014-2015. The aim of this comparative study is to document the diverse characteristics of occupationally specific working places in Asia and Europe. The participatory photo interview method, used in this study, 
serves to enable the analysis of working places as learning spaces from the perspective of persons involved in the learning activities at work (Kolb, 2009; Lorenz, Kolb, 2009).

For the pilot study described in this article, two owners of a very small hotel in Denmark ("The B\&B-House - only 30 minutes from Copenhagen") were asked to document their learning at work using the auto-photography method. After a preparatory introductory conversation with the two involved persons, both have been taking pictures of the learning opportunities they experienced at their particular workplace for two weeks. Lastly, an interview about working place as learning space has been conducted by using the photos with each of the involved persons.

\section{State of the art - working places as learning spaces - spatial dimensions}

For some time, there have been several attempts to develop a united theory, where learning is seen both as a cognitive and a social process - or, as Anna Sfard (1998) describes it in her article "On Two Metaphors for Learning and the Dangers of Choosing Just One" - to use both metaphors: the one on learning as acquisition and the one on learning as participation. The same tendencies can be seen in the development of theory on transformative learning (Taylor, Cranton et al, 2012), workplace learning (Malloch, Cairns, Evans, O'Connor, 2014) and language learning (Kramsch, 2004).

For example, researchers working on the development of transformative learning theory are seeking for a more unified theory, where it would no longer be necessary to think in terms of dualisms such as rational vs. extra-rational processes, individual change vs. social change, autonomous learning vs. relational learning. These researchers argue that the two perspectives can coexist: "It may be that for one person in one context, transformative learning is a rational endeavour; for the same person in another context, it could be emotional and intuitive; in some contexts, social change may need to precede individual change, and in another context, individual transformation drives social transformation, and so forth" (Taylor, Cranton et el, 2012, 3).

These complex inter-relationships between adult learners and environments, including workplace environments, are not yet clearly understood (Kersch, Waite, Evans, 2012). Especially because these inter-relations are constantly changing: as the editors of the book "Changing Spaces of Education" state in their introduction: "Widespread access to and use of information and communication technologies (ICTs), and the emergence of a knowledge based economy necessitate an 
understanding of the plurality of spaces (such as homes, workplaces, international space and hyperspace) within which learning can take place, as well as the "nontraditional" stages in the life course at which it occurs" (Brooks, Fuller and Waters, 2012, 1).

As a result, workplaces are now being acknowledged as sites for learning in various configurations, contributing to lifelong learning, personal development and social engagement of individuals (Evans, Waite, Kersh, 2011). Thereby, work is defined as "more than employment for remuneration and the considerations of place as more than a physical location for learning" (Malloch, Cairns, Evans, O'Connor, 2011, 1). "The ways in which adults learn in and through the workplace are rooted in educational trajectories and their complex intertwining with social institutions (of labour market, workplace, community) and social roles (of employee, citizen, family member) at different stages of the life-course" (Evans, Waite, Kersh, 2011, 355).

Persons learning at work belong to a complex system of actions and interactions, which is complicated to study. The metaphors such as "ecology" and "space" begin to replace the above mentioned metaphors of acquisition and participation in order to find a way to understand the complexity of factors without losing the entire multidimensional picture. There is a general tendency across the social and human sciences to move away from more modernist conceptions of linear progress and development through time to the notions of simultaneity and diversity, and thereby interest in space and spatial theory (Brooks, Fuller, Walters, 2012).

Here, space is understood relationally as "constituted and given meaning through human endeavour" (Singh, 2007, 197 cited in Brooks, Fuller, Waters, 2012, 2). Contrary to the notion of space as a static, passive geometrical phenomenon, space "is continuously produced through socio-spatial relations ... space is conceived as a product of cultural, social, political and economic interactions, imaginings, desires and relations" (ibid.). Or, as Henri Lefebvre stated in 1991, space is both constituted through social relations and constitutive of them (Lefebvre, 1991).

\section{Approach - learning (also at work) as a complex multidimensional process}

The study reported in this paper is based on the social constructivist worldview, i.e. that human beings are actively constructing their own subjective "realities" according to their own identity in their particular situation. In other words, individuals develop subjective meanings of their experiences (Creswell, 2007). These meanings are varied and multiple and are developed and negotiated socially and historically. 
Therefore, for the purposes of this study, human learning is considered as experience which adapts the notion of experience as both personal and social (Dewey, 1938). According to Dewey, both the personal and the social are always present. People are and need to be understood as individuals, but they are at the same time always in relation, in a social context. For this study, a criterion developed by Dewey is especially relevant - continuity - the notion that experiences grow out of other experiences, and these experiences lead to further experience (Dewey, 1938). "Wherever one positions oneself in that continuum - the imagined now, some imagined past, or some imagined future - each point has a past experiential base and leads to an experiential future" (Clandinin, Connely, 2000, 2).

Thus, in this study, learning is understood from the ecological, spatial, sociocultural perspective, with a focus on spatial dimensions of learning (time, place and interaction). The ecological perspective implies that "activity in a meaningful environment generates affordances for enhancing that activity and subsequent activities" (van Lier, 2004, 80). The ecological view on learning entails that the context (physical, social, symbolic) is a central element in learning (van Lier, 2004).

Learning is an extremely complex multidimensional process that happens differently to everyone and involves a host of subjective parameters, such as perceptions, emotions, attitudes and values. Learning, aside from being a cognitive process, is also an emotional and social process. This happens in the interaction between people and their environment on the basis of their experiences (van Lier, 1996, 2010). The socio-cultural perspective implies that historical, cultural and symbolic activities provide resources for learning and action.

The perspective of social ecology provides a way into understanding the complexities of factors that impact on learning in the workplace, through the interplay factors, structures, processes and environments (Evans, Waite, Kersh, 2011). This interplay is not restricted to the workplace and can include all other life spaces of the individuals.

The concept of learning in, for and through the workplace applied in this study (Evans, Hodkinson, Rainbird, Unwin, 2006), underlines that social processes shape employees' perceptions and attitudes towards engagement in workplace learning and influence their professional and personal development and life chances within the workplace and beyond (Evans, Waite, Kersh, 2011). Therefore, the learning continuum between formal, non-formal and informal learning is a key framework for understanding how learning opportunities for professional and personal development at work are distributed, structured, experienced and used (Chisholm, 2008). The way employees perceive their learning at work is often associated with their perceptions of the space in which their learning is taking space (Kersh, Waite, Evans, 2012). 


\section{Methodological choices - studying lived experiences}

When understanding learning spaces at work as constructed by the individuals who are participating in the everyday activities at work, some fundamental choices should be made when deciding on the methodological approach to the study. An attempt to come as close as possible to persons' lived experiences and personal reflections about their own learning (van Manen, 1991) has been applied in this study.

To analyse working places as learning spaces from the perspective of persons involved in the learning activities at work, a participatory photo interview method was used to invite the participants to reflect on their own learning (Kolb, 2009; Lorenz, Kolb, 2009). By capturing learning moments in their everyday activities at work in exactly the way that the participants perceive them as learning moments, and then telling the researchers about those moments, they allow us to get an insight into their unique, practical, emotional and symbolic life in the concrete historical context (Kramsch, 2009).

The photo interview method is chosen because of its potential for discovering local perspectives on daily life and involving local actors in a scientific process. "Using the photo interview, local cultural and social settings become visible as residents take photos that show their perspectives on the research question and their experiences with and understandings of the local context" (Kolb, 2008, p. 1). The photo interview can both provide us with the first accounts of data about learning, as well as encourage active participation involvement in the research process (Lorenz, Kolb, 2009).

After a preparatory talk, two owners of a very small hotel in Denmark ("The $B \& B$-House") were asked to document their learning at work using the autophotography method. After two weeks of photographing and reflecting on their own learning at work, two interviews were conducted with both employees. The empirical material analysed in this study consists thereby of a preparatory talk (first conversation), pictures taken by the two employees at their workplace during the two weeks, and an interview with each person about the pictures and their reflections. In this paper, the main focus is on the analysis of the first conversation with the study participants. Though, in the process of analysis all information from the pilot study project at "The B\&B-House" is used.

The process of analysis is inspired by the recently developed method of analysis "analyzing in the present" by Line Ravsbæk and Lene Tanggaard, where these authors focusing on the significance of the reflexive open minded process of a researcher listening and re-listening to the empirical material (Revsbæk, Tanggaard, 2015). The authors describe the process of analysis as a process of "continuously opening up the empirical material in a reflexive, breakdown-oriented process of 
analysis" (Revsbæk, Tanggaard, 2015, p. 376), recognizing the non-linear complex process of analysis where the researcher and the researched are closely interconnected.

By listening and re-listening to the qualitative material, the spatial categories as they are used in the narrative approach seemed to be useful to understand the differences in the perception of learning at work by the two involved persons. Already in the first conversation, analysed in this paper, a set of terms could be applied that in the narrative theory create a metaphorical three-dimensional narrative inquiry space, with temporality along one dimension, the personal and the social along a second dimension, and place along a third (personal and social (interaction), past, present, and future (continuity); combined with the notion of place (situation) (Clandinin, Connely, 2000, 50).

The usefulness of employing spatial analysis is documented in the previous research, for example by Brooks, Fuller and Walters. They state that by employing spatial analysis it is possible to indicate the differences across physical and virtual spaces, explore the relationship between structure and agency, and the relationships between social processes at different scales, as well as to interrogate some of the taken-for-granted assumptions about education and learning (Brooks, Fuller, Waters, 2012).

\section{Context - desire for travelling as a drive for change of profession}

The case presented in this paper is very atypical, but very interesting for the research. The chosen enterprise is a small hotel in Denmark - a Bed and Breakfast House - owned and driven by two persons who have retired from jobs that they had all their working lives. They work and live together in their own house, which at the same time is a hotel and thereby their work place as well. The enterprise is thereby a hybrid organisation - somewhere between organisation and civil society, and a good example of what research on workplace space describes as plurality of spaces (such as homes, workplaces, international space and hyperspace) within which learning can take place, as well as the "non-traditional" stages in the course of life in which it occurs, as mentioned earlier in this paper.

"The B\&B-House" is a small-size enterprise located in Denmark near Copenhagen. It is owned and driven by two persons, who live and work together in the House. The hotel has two rooms for guests, a shared bathroom and a kitchen. After 10 years of work, the hotel have $500+$ satisfied guests a year, who secured them a Trip Advisor medal in both 2013, 2014 and 2015 and a Super host medal in 
2014. At the time of the interview, the Bed and Breakfast House was number 4 on the small hotels' ranking list in Denmark.

In one of the interviews, the hosts of "The B\&B-House" tell that the idea to open their house to guests came because of their own love of travelling. After retiring, they wanted to ensure that they still could afford travelling. On the hotel's website, you can find the following text:

"Your hostess Eva says: "My husband and I have always travelled a lottogether and separately, all over the world. Curiosity and open minds combined with our language capabilities have given us a lot of good friends in many countries. Though we love to travel abroad, we also take the time to visit friends in our beautiful Denmark - and we have always welcomed guests in our home in Karlstrup Village." (From the webpage of "The B\&B-House").

The idea of converting part of a private home into a bed and breakfast was born during a trip to Lisbon, where the couple stayed in a similar establishment. Later in Denmark the two entrepreneurs learned how to run a bed and breakfast by opening one themselves. They learned a lot about running an enterprise, about peoples' psychology, developing new concepts for their work and many other practical aspects, and by using all their languages: "We speak the following languages: Danish, English, German, French, Spanish, Italian and Portuguese. Being Danish, we also understand Norwegian and Swedish" (From the homepage of "The B\&BHouse").

In the interviews, the owners of "The B\&B-House" shared with the researcher that they definitely like to run a Bed and Breakfast at their home. And they are very proud of their success in the hospitality field. The two persons claim to have always been good at working together, at dividing tasks between each other and at helping each other.

Naturally, we also need to mention, what positions the two learning-at workpersons have held during their entire working life, before they retired and opened their home for guests. Eva has been a language teacher at school and has taught English, Danish, German, domestic science - and to private students also Italian, French and Spanish. Asger has been a math, history, geography and biology teacher as well as modelling arts and visual arts, woodwork and domestic science teacher. For 23 years, he also worked as the deputy school principal at a large school.

The conversation about learning analysed in this paper took place in the nice living room, full of books and interesting art at "The B\&B-House". The hosts served coffee. The conversation did not go as planned, because of an extensive discussion on the notion of learning. 
The first interview - "I have learned - it is about something that happened in the past"

In my analysis of different perceptions of learning at work, I would like to focus on one excerpt from the very first conversation with the two owners of "The B\&BHouse". The conversation took place immediately after the two study participants were introduced to the information letter, specifically developed for this pilot study. The conversation about the notion of learning begins after the two persons have read the instructions stated in this letter. The text started as follows:

"Information for the participants: Please take some pictures of those situations where you are thinking: "I am learning!" or "I have learned!" or similar. You can choose the ..."

Excerpt 1: Conversation about learning

Elina: So ... how do I learn in my every day at work ...

Eva: So, if there is "I have learned" it doesn't mean a long time ago, Asger!

Asger: You learn something, and you learn something all the time, right? And something of it is the further development of something learned before. I can for example, say: "Earlier I took the big fat computer under my arm and was sitting there and working, later I got an iPad, right? I have learned to use iPad for our enterprise...

Eva: Yes, yes ... but no one is interested in this right now, Asger, don't you understand!? It is right now! What do you learn today?! What do you learn this afternoon!? Or tonight when he arrives ....

Elina: But it doesn't have to be so ... .... [complicated] ... Here is your working place, and if you are thinking "now I have learned something" or "I am learning now!" - take a picture of it! And you don't have to think further about it ... just take pictures! (laughs)

Eva: But not anything with something that you have learned long time ago? You know, it is far too formal what you have got there! (is saying this to Asger) 
"I have learned - It is about something that happened in the past!"

Asger: I am quite formal (laughs loud).

Asger: (reading the information letter) I am learning or I have learned or similar ... I "have learned" - it is damn something that happened in the past!

Eva: No! Listen! In this situation, both can be used, because you have learned. It is not the same as it is ... Elina is saying that it must be a moment when you are suddenly thinking "Ahh, here I just learned something!" - so it is - I have learned.

In this conversation, initiated by the interviewer and guest of "The B\&B-House" (and author of this paper), Eva and Asger (the owners of the enterprise) are discussing the wording in the information letter, which they have just received from the interviewer. They start out by analyzing the grammatical form of "I am learning" and "I have learned" and begin to discuss of which kinds of learning they should take pictures. For Asger, "I have learned" means something that happened in the past. He begins to elaborate on learning as a product and thinks of a concrete example where he has learned something new - to use an iPad instead of a computer for his work. For Eva, however, learning is about something that happens in the concrete moment (and place): "It must be a moment when you are suddenly thinking "Ahh, I just learned something!". This means that Eva considers learning much more as a process than a product.

From the very beginning of this conversation, we understand that all three participants have their own visions of learning which differ from each other. Later, the analysis of the pictures taken by the participants about their learning at work will show that each participant has interpreted the wording in the information letter in a way in which he/she understands her/his learning in everyday activities at "The B\&B- House". We will later find out that Asger actually considers that he is learning on the basis of previous experience that results in new knowledge and skills. Later on, we will also find out, that Eva learns in the communication both with herself when thinking and via verbal or non-verbal communication with other persons.

After intensive listening and re-listening to this interview and at the same time reading and rereading the book on narrative inquiry by Claninin and Connely', I realized that in this particular conversation we are able to follow what Clandinin and Connely call a metaphorical three-dimensional narrative inquiry space, mentioned earlier (Clandinin, Connely, 2000). Here we can follow temporality along one dimension, the personal and the social along the second dimension, and place along the third. 


\section{Three dimensional narrative space in the conversation about learning}

Analysing this conversation, we can see that the discussion about learning goes much deeper than just into the discussion of the grammatical tense in the wording from the introductory material. I will now describe the conversation chronologically by using the categories used in the metaphorical three-dimensional narrative space mentioned earlier in this paper: temporality - past present and future (continuity), personal and social (interaction), and place (situation).

The interviewer (Elina) is introducing the conversation theme and tries to initiate the process of taking pictures by saying a very general "how do I learn in my every day at work..." statement. As a researcher who took part in the development of the study design for the pilot project, Elina has a clear picture of what should happen during the two weeks devoted to taking pictures at work. Elina knows that the researchers are interested in documenting the diverse characteristics of occupationally specific working places in Asia and Europe. She imagines that these characteristics can be physical, virtual, cognitive, social and affective and that the participants of the study will experience the taking of pictures of very different activities or situations - as learning situations. It is also the reason why she mentioned the word "situations" in the introductory material, which probably have pushed the participants in a specific direction - in thinking about moments in time and space.

The first phrase uttered by Eva tells us that Eva and Asger have already discussed the issue of learning before this conversation. That fact tells us that this particular conversation is part of a string of events on a timeline somewhere between the past and the present.

The same sentence uttered by Eva indicates that the content of the discussions was probably discussed between the two participants, and continues further in this conversation - the above-mentioned discussion about the grammatical tense and the notion of tempus in the phrase "I have learned". Does this form refer to an action taking place in the past? Is this action finished or unfinished? Is this action still ongoing or is it finished?

The first passage uttered by Asger is where he continues reflecting on the learning as process or result, as well as the continuity in this process: "You learn something, and you learn something all the time, right? And something of it is the further development of something learned before". Here, Asger expresses a very concrete idea about learning that happens continuously. The question is when can we call it learning, and when can we consider learning as a product that can be documented? At the same time, the role of the different experiences is articulated in these two sentences: new learning is the development of something learned before. 
"I have learned - It is about something that happened in the past!"

Then, Eva tries to defend her own vision of learning, and how she has understood the information provided to participants. It seems that Eva clearly understood that the pictures to be taken must capture the learning moments something that happens right now, right here. Thus, both time and place dimensions are present here. Eva imagines the learning moment right now or in the future, for example, this afternoon. Something must happen if you want to capture the learning. Suddenly, Eva says: "Or tonight, when he arrives ... ". It would not be possible to understand the meaning of this sentence without hearing Eva's stories about her learning in the second interview. When interviewing Eva for the second time, we will find out how important the third dimension of the metaphorical threedimensional space is to Eva's understanding of learning - the one about the interconnection between the individual and the social, the one about the communication. Already in this preparatory talk Eva has a vision that she can start taking pictures when a guest arrives, and not before. In the beginning of the second interview, Eva says: 'Unfortunately, I haven't learned that much, we didn't have so many guests". Essentially, Eva learns together with, from or near people.

Then, feeling that conversation becomes more complicated, Elina tries to calm her conversation partners down by saying that they do not need to think that much. They should just think about learning and take pictures. Look around, where do you learn? However, Eva is still trying to follow her agenda on convincing her husband that only pictures of "new" learning can be taken. It begins to look like a competition, where one participant wants to take more pictures than the other if one is allowed to take pictures of "old" learning alongside the "new" learning. Another issue becomes evident, namely formal and informal learning, which have not been discussed with the participants prior to this conversation. Eva expresses something that we cannot document or measure, but only feel intuitively by listening to and reading her words. There is a formal learning, perhaps school learning, and there is learning that cannot be measured. Later, we will find out that Eva understands learning in a philosophical way using much of her time thinking and reflecting: Is this learning?

Later in the conversation as can be seen in the next passage, Asger agrees with his wife that he is quite formal. It seems that this kind of discussion happens often between them. However, Asger does not give up. He reads and rereads the information letter and reflects on the wording: "I am learning or I have learned or similar ... I "have learned" - it is damn something that happened in the past!". When Asger shows the pictures he has taken, we are able to see that he has captured the products of his learning: "the new vacuum cleaner that is very light - because he has found out that it is much easier to carry it to the second floor".

Eva continues to defend her grammatical knowledge saying that the sentence "I have learned" can be both used about something that happened in the past and 
something that you learn right now, because the action is not finished: "In this situation, both can be used, because you have learned". But she will not give up her notion about the moment in time and the idea that comes to your mind at the particular moment of time: "Elina is saying that it must be a moment when you are suddenly thinking "Ahh, here I just learned something!" - so it is - I have learned." When analysing this conversation, the following dimensions can be identified:

\section{Time, space and communication in the conversation about learning:}

TIME

- $\quad$ just happened?

- $\quad$ happened some time ago?

- $\quad$ finished or not finished?

- $\quad$ a process?

- $\quad$ a result?

- $\quad$ capturing only new learning?

- $\quad$ learning happened only during two weeks?

- $\quad$ completely new experience?

- $\quad$ further development of something?

\section{SPACE}

- $\quad$ physical, virtual, emotional, spiritual, ... space

- $\quad$ cognitive, emotional, social factors

INDIVIDUAL - SOCIAL

- $\quad$ intrapersonal

- $\quad$ interpersonal

- $\quad$ between individuals and environment

- $\quad$ communication, interaction, thinking

\section{Two persons - two visions of learning}

The analysis of the empirical material collected in this pilot study show that all three persons participating in the analysed conversation have different perceptions on what learning is. By using spatial categories as time, space and inter- and intrapersonality, we are able to describe these perceptions. Since Elina's understanding 
"I have learned - It is about something that happened in the past!"

of learning is described in detail in the theoretical reflections of this study, we will focus on the two participants of the study: Asger and Eva.

\section{Asger's vision of learning - practical learning for success}

When Asger tells about his learning at work, he tells that he is learning everywhere in the house. He highlights places where he is constantly learning, for example, in guest's rooms: "Here, you gradually learn about places where dust settles the most. It is always in the corners. Dirt always lies in the corners, under the bed...". This is a kind of practical learning that happens over a longer period of time. But it can also be called learning, when the new knowledge or skills are achieved. Especially, when he speaks about his office - his computer and his phone - he says: "Much of learning happened here around the computer". Here, he is using the past tense and thereby illustrating that the process of learning is finished, and that today he has been running the enterprise well.

Some of the examples on everyday tasks at the enterprise, which have been acquired during the years of working in the hospitality business by solving problems, analysing, communicating and being creative are homepage developments, promotion of "The B\&B- House" on these websites, planning and conducting daily work tasks. For Asger, good learning results in the appreciation from the outside. Probably that is the reason why it is important for Asger to communicate to the outside about "The B\&B-House": he writes a letter for the local newspaper, gives interviews to the national magazine, and he also agreed to participate in our project. Furthermore, his work has been appreciated by several excellent reviews from his guests. As Asgers puts it himself, he and Eva have learned that they are good at hosting guests, which makes the guests always come back to "The B\&B-House".

In addition to the numerous practical activities, Asger tells how he learned how to make their guests take the tourist brochure with them when they leave - you place it on the bed and that will ensure that they will take it with them. How to ensure that the night lamp does not break all the time by falling down - make it from plastic. How to make hard work easier - buy a smaller vacuum cleaner!:

"Here is a picture of two vacuum cleaners. I have learned this in the guests' room. This one is heavier than the other, and it has a long electrical cord. If we have a guest, who has lived in the room for four days, I take the big vacuum cleaner and do careful vacuum cleaning at the room upstairs. But if we have had a guest for one night only, and I have done extensive cleaning the day before, I can take the little one and easily just clean the 
small dust bunnies. And so it is done. It is much faster, and it is easy to carry. Therefore, we bought the second vacuum cleaner. I learned it when I was carrying the old one all the time." (From the second interview with Asger).

Asger does not think that he learns when he is doing the routine work, for example when he works at the laundry room or when he washes the dishes. Only if he begins to do these practical everyday activities in some new ways.

For Asger, learning is a result of a problem-solving process, experiments take place, the previous experience is used, and the situations are analysed. We can therefore talk about continuity in time, a non-linear process that happens somewhere between the past, present and the future. All the learning which Asger talks about is work-related and happens at the workplace, physically or virtually from the computer at the workplace. He likes when this learning is visible and can be documented in some way. Therefore, Asger communicates outside the workplace, but the communication inside the workplace also has an important role.

\section{Eva's vision of learning - the impulses of thought}

For Eva, learning is a process or a moment in time and place - a kind of impulse that appears inside the head and initiates thinking and reflection. And these moments are often connected to people. The first thing Eva tells during the second interview is that she did not learn that much, because they did not have many guests.

Eva is learning with and through people. The first learning place she points out is the stairs right in front of the entrance door of the house. There she meets people, gets the first impression of them, speaks to them, changes her prejudice about people, learns from them about new countries, new perspectives about others - and herself. She learns a lot about herself in the communication with others: "Here I am learning the most, here we are standing and speaking with people".

Eva's experiences have a different nature than Asger's experiences. Eva's experiences are a part of the process of observing people. They can help or disturb your ability to judge people. Eva constantly analyses what she feels about the persons, and she is also learning from it.

Eva sees learning as a process that happens here and now, something you experience at the particular moment of time and in a particular place. And it is also about communication. Eva has a clear vision of what experience is: "Of course, you are learning in your business to do things better and better, more right, but you have only learned it when you use it the next time. This is the difference between learning 
and experiencing. You have not learned anything if you are not capable of using it." Furthermore, being a curious person, Eva is learning by reading both the many books in their house and the internet, because she is interested in new places, new cultures, and new experiences.

\section{Discussion - which questions can we ask?}

In this paper I could only present a flash of all the interesting and complex empirical material that we collected with the help from the two owners of "The B\&B-House". The aim of the analysis was not to find answers, but it can be used to ask new questions.

Later, an in-depth analysis of the notion of learning will be analysed together with the data from other pilot projects. Pictures and interviews will be analysed. Consequently, each case will be described and then compared with other cases.

The aim of my paper was to find out how different visions of learning can be constructed at a particular workplace and illustrate this with my empirical material. Therefore, I attempted to apply the spatial categories as developed in the narrative theory.

Many questions arise from this analysis. Let us discuss one of these questions: Can you re-learn something? Telling me about the practical things Asger learned by running "The B\&B-House", he talks about something he learned and then relearned. It is about chocolate:

"It happened right there! (points at the bed) Yes, right there on the pillow (laughs). Right on the pillow. Because I have learned... I have learned it, then re-learned, and then learned again. Because in the beginning, we did it, we put a little Mon Chéri chocolate on the pillow. It was sweet and nice. People were actually happy about it. Then we thought, maybe it is too expensive. It costs about 3- 4 Danish krona every time. So we stopped doing it. But now we began to do this again. We thought that it is stupid not to do this. No problem with those 3-4 krona. So... I have learned, then I have re-learned, and I have learned it again (laughs). Now we are placing a small chocolate on the pillows again".

This is one of the questions that could be dealt with in this study. Is it possible to speak about re-learning? Should this example be categorised as making decisions, or is it a part of a learning process that happens over time? 


\section{Conclusions}

The three dimensional narrative space is visible in all conversations with both participants. All three of us together are moving backwards and forwards on the timeline, when speaking about time moments, periods of time and continuity. We are located in the nice living room of "The B\&B-House", but our thoughts are travelling in time and space, in our individual thinking spaces and in our social worlds. When telling stories, we are taken back to our memories into our emotional worlds, into the past and future. We are the products of our lives, our education, our families, and our friends etc. Everything is interconnected into complex systems that have influence on our learning and our future lives.

Although our two project participants have been living together for many years, they have very different perceptions of what learning is. Knowing that the two persons have been teachers, we can even make connections to the subjects they taught at school. Asger has been teaching science subjects, where problem-solving and experiments are the way of learning, for example math and physics. Eva has been teaching languages, and she has a very linguistic perspective on understanding learning.

The goal of this paper was to understand how different understandings of learning have been constructed by two persons from the respective workplace and exemplify the three spatial dimensions and the differences between these with an empirical example from the pilot study.

The example described in this paper is what we can call a hybrid space - a space when work and life meet each other and create new dynamics and inspirations for learning. It is also what Kersh, Waite and Evans (2011) call learning at the nontraditional stages of life, since the two B\&B owners use their retirement to run an enterprise. We can follow how desire for travelling can inspire the long learning process, how the two persons construct the space of social relationships. We can also link it to the wider scale of activities, and how new forms of learning require new forms of self-governance, and how this process happens naturally because both persons love what they do.

The changing nature of work has some implications for learning at work. With this paper I will argue, that we need more research done from the subjective perspective of the people involved in learner activities at work. Further research on the complex inter-relationship between adult learners and environments, including work places, can help us to develop learning activities at work needed and used by employees. 


\section{References}

Alvesson, M., and D. Kärreman (2011). Qualitative research and theory development: Mystery as method. London, England: SAGE.

Brooks, R., A. Fuller and J. Waters (Eds.) (2012). Changing Spaces of Education. New perspectives on the nature of learning. Routledge: London and New York.

Brinkman, S. (2014). Doing Without Data. In: Qualitative Inquiry, Vol. 20 (6), pp. $720-725$.

Chisholm, L. (2008). Re-contextualising learning in second modernity. In: Research in Post-Compulsory Education, Vol. 13, No. 2, pp. 139-147.

Clandinin, D. J. and F. M. Connelly (2000). Narrative Inquiry. Experience and Story in Qualitative Research. San Francisco: Jossey-Bass Publishers.

Creswell, J. W. (2007). Qualitative Inquiry \& Research Design. Choosing Among Five Approaches. London: Sage Publications.

Evans, K., H. Hodkinson, H. Rainbird, L. Unwin (2006). Improving Workplace Learning. New York and Abindgon: Routledge.

Evans, K., \& Waite, E. (2009). Adults learning in and through the workplace. In K. Ecclestone, \& G. Biesta (Eds.), Transitions and Learning through the Lifecourse, pp. 162-181. Abingdon: Routledge.

Evans, K., E. Waite, N. Kersh (2011). Towards a Social Ecology of Adult Learning in and through the Workplace. In: Malloch, M., L. Cairns, K. Evans, B. N O'Connor (Eds). (2011). The Sage Handbook of Workplace Learning. Sage, pp. 356-370.

Dewey, J. (1938). Experience and Education. New York: Collier Books.

Guile, D. (2010). The Learning Challenge of the Knowledge Economy. Sense Publishers: Rotterdam, Boston, Taipei.

Evans. K., E. Waite and Natasha Kersh (2012). Towards a Social Ecology of Adult Learning in and through the Workplace. In: Brooks, R., A. Fuller and J. Waters (Eds.) (2012). Changing Spaces of Education. New perspectives on the nature of learning. Routledge: London and New York, pp. 356-370.

Kersh, N., E. Waite and K. Evans (2012). The spatial dimensions of workplace learning. In: Brooks, R., A. Fuller and J. Waters (Eds.) (2012). Changing Spaces of Education. New perspectives on the nature of learning. Routledge: London and New York, pp. 182-202.

Kolb, B. (2008). Involving, Sharing, Analysing - Potential of the Participatory Photo Interview. In: Forum: Qualitative Social Research, Vol. 9, No. 3.

Kramsch, C. (Ed.) (2004). Language Acquisition and Language Socialization. Ecological Perspectives. Continuum: New York.

Kramsch, C. (2009). The Multilingual Subject. What Foreign Language Learners Say about their Experience and Why it Matters. Oxford University Press. 
Lefebvre, H. (1991). The Production of Space, Oxford: Blackwell.

Lorenz, L. S., B. Kolb (2009). Involving the public through participatory visual research methods. In: Health Expectations, An International Journal of Public Participation in Health Care and Health Policy. Vol. 12, Issue 3, pp. 262-274.

Malloch, M., L. Cairns, K. Evans, B. N O'Connor (Eds). (2011). The Sage Handbook of Workplace Learning. Sage.

Noland, C.M. (2006). Auto-Photography as Research Practice: Identity and SelfEsteem Research. In: Journal of Research Practice. Innovations and Challenges in Multiple Domains, Volume 2, Issue 1, Article M1.

Revsbæk, L and L. Tanggaard (2015). Analyzing $\mathrm{n}$ the Present. In: Qualitative Inquiry, Vol. 2 (4), pp. 376-387.

Singh, M., F. Rizvi and M. Shrestha (2007). Student mobility and the spatial production of cosmopolitan identities. In: Gulson, K. and C. Symes (Eds.). Spatial Theories of Education: Policy and Geography Matters, Routledge: New York, pp. 195-214.

Sfard, A. (1998). On Two Metaphors for Learning and the Dangers of Choosing Just One. Educational Researcher, Vol. 27, No. 2 (Mar., 1998), pp. 4-13.

Taylor, E. W., P. Cranton and Associates (2012). The Handbook of Transformative Learning. Theory, research, and Practice. Jossey-Bass: San Francisco.

Van Lier, Leo (1996). Interaction in the Language Curriculum. Awareness, Autonomy \& Authenticity. Longman.

Van Lier, Leo (2004). The semiotics and ecologyof language learning. Perception, voice, identity and democracy. In: Utbildning \& Demokrati, Vol. 13, nr. 3, pp. 79-103.

Van Lier, Leo (2010). The ecology of language learning: Practice to theory, theory to practice. Procedia - Social and Behavioral Sciences. Elsevier.

Van Manen, M. (1997). Researching Lived Experience. The Althouse Press. 